\title{
Walmart China Face the Marketing Strategic Issues and What's their Future Plan
}

\author{
Mingchen Yuan ${ }^{1 *}$, Ningxin Zhang ${ }^{2}$, Zu Guang Wong ${ }^{3}$ \\ ${ }^{1}$ College of Art \& Science, Syracuse University, Syracuse New York, 13244, US, yuanmingchen922@ gmail.com \\ ${ }^{2}$ English School Attached to Guangdong University of Foreign Studies, Canton China, 510440, \\ Lorraine031219@163.com \\ ${ }^{3}$ St. John's School, Vancouver, British Columbia, Canada, V6K 2J, Jessiex324@gmail.com
}

\begin{abstract}
The purpose of this SWOT analysis is to demonstrate that Walmart has the opportunities to achieve localized transformation and have competitive strength by using effective supply chain logistics and E-commerce locally; however, the company will need to act swiftly to overcome its weaknesses in its management culture and the failure to read Chinese culture and consumption habits as well as the threat of local supermarkets gaining more brand loyalty.
\end{abstract}

Keywords: Walmart, Retail, Online Commerce, Grocery, Management, Culture

\section{INTRODUCTION}

Walmart entered China in 1996 with its first location in Shenzhen. By adapting its business model to cultural differences and sourcing locally, Walmart China has been able to avoid some of the pitfalls that foreign retailers face in China [1]. As of January 2020, there were in total 438 Walmart stores in China, including 412 retail stores and 26 wholesale stores in more than 180 cities and by May 2020, 96,600 associates work for Walmart China [2].

Walmart today in China operates in three retailing formats: Supercenters, Sam's Club, and Neighborhood Markets, all of which cater to different consumers' needs. Supercenters mainly aim at saving consumers' time and money. Their business model allows them to sell commodities with low prices harmonized across all their shops nationwide. Sam's Club in China is a membersonly warehouse and has a similar business model as Costco in China, which provides low-cost, bulk products for both business and personal use. Neighborhood Markets are located near residential areas, for consumers' daily shopping needs [1].

In the work, we went through the data and research in recent years demonstrating the current problems that Walmart China facing toady. Also, by giving direct and credible resources in order to clarify the future benefits.

\section{WALMART'S STRENGTHS}

\subsection{Strong cooperation with local E-commerce}

To adapt to the needs of Chinese consumers, Walmart worked with China's second-biggest e-commerce retailer-JD.com. In 2020, e-commerce retail accounted for about $25 \%$ of total retail sales in China [2]. Walmart subsequently paid $\$ 1.5$ billion for a $5 \%$ stake in JD.com which has since then risen to $12 \%$ [3]. Walmart and JD.com invested $\$ 500$ million in Dada-JD Daojia, an online grocery store with delivery services. [4].

According to a survey conducted by McKinsey, 25\% of people in China began using grocery delivery, and 50\% started using more of this service since the outbreak of Covid-19 [5]. By cooperating with JD.com, consumers can pay for items from Walmart through the miniprograms on WeChat or JD.com's app. WeChat' viral trend and the leading social media platform, which integrates e-commerce. Groceries and daily necessities after the order is placed can be shipped to local consumers immediately which is especially safe and effective during the pandemic [3].

Walmart was heavily influenced by JD.com when it opened its smart supermarket as well. 90\% of Walmart's storage was s located on JD Daojia which helps Walmart downsize its stores. Like Walmart's competitors, this allows Walmart to move more of its inventory online [1] 


\subsection{Effective Supply Chain Logistics}

Walmart has efficient supply chain logistics which allows it to transport materials and products all around the world. Over 100 million dollars was invested to build Walmart's South China Fresh Food Distribution Center which began operating March in 2019. Currently, this center serves over 100 Walmart in Guangdong and Guangxi and delivers 165,000 boxes of products each day. The center is built according to international leading standards and can save more than 4,000 kinds of food that need temperature regulation. The system used is based on ammonia refrigeration. In different temperature zones, other types of refrigerants are also used to improve efficiency and sustainability which allows the storage area to save more than 330,000 kilowatt-hours per year [6].

In the cold chain stage of transportation, products must be cooled before they are loaded onto temperatureregulated trucks according to Walmart's requirements. All trucks used for transportation are installed with a "transportation monitoring system". This system checks whether a product is pre-cooled to the set level or not before loading. Other equipment is equipped on the truck to monitor the temperature inside the truck during transportation to ensure that the products arrive fresh and of high quality [6].

The supply chain Walmart uses utilize data from the Data Lake International Big data platform to enhance data storage and analysis capabilities. New mobile applications are used for supply chain managers to visualize and monitor performances. The distribution center has also established a quality testing laboratory to carry out frontline testing on problems such as food legality and pesticide residues [6].

\section{WALMART'S WEAKNESSES}

\subsection{Inappropriate management style}

There is a huge cultural difference between America and China, however, the human resource managers in Walmart failed to consider the local Chinese culture. The following factors have been the genesis of inequality, tensions around labor, workplace rights, and led to the strike involving about 40 workers at the coastal Shenzhen branch [7].

\subsection{Decentralization and centralization}

China is heterogeneous and supports a decentralized process, while the United States is homogeneous and supports a centralized process. As a result, Chinese managers need more power because they have extensive networks. Americans, on the other hand, do not ascribe to the power distances idea. This is because, with a centralized management process, the supplier network is moderate, hence no need for more power [7].

\subsection{Collectivism and Individualism}

China has a collectivist culture; The Chinese believe that individual success results from teamwork. Therefore, incentives or rewards must be collective, not individualized. The principle of equity is embraced in their incentive system. For example, when setting wages, salaries, and other benefits, Chinese organizational leaders often emphasize a worker's education and working experience. When it comes to promotions, factors such as personal relationships and political affiliations get more attention. Instead of taking all these factors into account, Walmart emphasizes individual performance. The salary and reward system is also based on individual effort very different from the Chinese approach [7].

\section{WALMART'S OPPORTUNITIES}

Walmart's strategies have not achieved a growth rate similar in the United States. However, with 25 years of accumulation of Chinese market experiences and strong financial support. Walmart strengthened in Chinese industry and the capability to seize the market share of the domestic retail industry. In the following pages, the analysis of the current trends in the Chinese retail industry and Walmart's reaction to the future benefit provides a deeper understanding of the business model in China.

\subsection{Chinese Huge Potential in Integrating Technologies in Retailing}

The Chinese market is rapidly changing to the overwhelming benefits of new retail both online and offline. "The market size is expected to exceed 3.3 billion" [8]. QR codes, facial recognition are the following major technical supports of why the Unmanned stores lead the local and domestic enterprises to keep up with the trend

Lower costs are the fundamental goals of the industry. The QR code enables the customers to check out the product by simply scanning the two-dimensional code on the product. Facial and behavior recognition traced by machine vision enhanced the shopping experiences by providing speedy payments procedures and an effectively check-out system. With the advantages of a quick payment method, the benefits are obviously observed. Customers save a huge amount of time on stop waiting in lines and are ready to check out. The stores also lower the operation costs by hiring fewer employees.

\subsection{Customers Services and Needs}

The integration of the database and the collection of customers information generate more specialized and 
personalized products. "First combines big data and deep learning to decompose the original images, train and learn different designer styles; secondly, according to users' preferences and other data matching to generate digital ads, the system selects the best ads after scoring" [9]. This effective approach to focus on the target group also improves the time efficiency and leading customers to find their needs in a shorter time with easier access.

With the gradual weakening of high labor costs faced by traditional offline retailing. The development of online customer service is gaining more popularity and growth rate. "The data shows the market of China's online customer service in 2017 was 64.4 billion yuan, with a compound growth rate of $10.62 \%$ " [8]. With the combination of technologies and online customer services. Customers can easily ask questions by taping screen either AI technologies with deep learning or live customers server will answer throughout the platform of big data and interpersonal communication of one-to-one private chat.

\subsection{Localization}

"Cultural value is a core aspect of the future consideration of Walmart's success in China. The western manager of Walmart focuses on more Westernized norms on the socialized Chinese market." [10].

It's not a valid method to hire managers taking charge of the Chinese market who do not have a clear indication of Individualism American and Collectivism Chinese. In other words, Chinese people like to have power and more teamwork.

In the following 5 to 7 years. Being a global organization, Wal-Mart will comprehend the local Chinese culture if it wants to get ahead of other retail chains in the Chinese market. In international business, understanding the cultural aspects that determine the association between an organization and its consumer is very important. Local employees who are familiar with local customs can understand the needs and consumption characteristics of local people, and know what channels can effectively reduce costs, so it can enhance the competitiveness of Walmart by assigning more local manger into the field.

\subsection{Getting Smaller}

The growth of large stores represented by hypermarkets and large supermarkets has weakened. "World Bank expects China's GDP growth rate to decelerate to $7.6 \%$ as China's salary growth is slowing down and severely impacting the region's consumer spending and retail sales" [11]. On the other hand, the growth of small stores represented by convenience stores and community stores has been advancing all the way.
"Senior Vice President of Walmart China announces that in the following 5-7 years, Walmart China plans to open more than 500 new stores while the community grocery store will be prioritized" [8]. Judging from market trends, the growth rate of Chinese consumers' demand for bulk consumption is slowing down, while the demand for replenishment and fast consumption has increased significantly. The rapid growth of consumer demand for replenishment and rapid consumption requires retail companies to serve consumers with higher density, closer stores, and more convenient ways.

The Shift to fresh and convenient reflects the difficulties faced by traditional primary and second-tier markets and the inevitable result of excessive store saturation and competition. "Online grocery shopping in China is driven by the country's rapidly growing middle class, high smartphone usage, and strong internet connectivity." [12]. Especially after the pandemic operating costs continued to rise, the format transformation of the retail stores is necessary to maximize cost control and refined operations. The development of compact stores has become a strategy in the future Chinese market.

\section{WALMART'S THREATS}

Walmart in China is facing two main threats, local supermarkets attracting more consumers and people there having different consumption cultures. Walmart faces the threat of local supermarkets such as Sun-Art Retail understanding Chinese consumers more and being more appealing.

Supermarkets such as the Sun-Art Retail group are attracting greater consumers compared to Walmart due to "Sun-Art's better understanding of their Chinese consumers" [11]. Sun-Art was able to combine the looks of a local Chinese street with a supermarket to better appeal to their customers. This has proven to be a competitive advantage for Sun-Art and they have benefited from this advantage as they have a higher market share than Walmart.

When Walmart expanded into China, it did not take into account the different consumption cultures that the Chinese consumers have. It was advertising and selling their goods like what it did in America, which now has become a threat to them. There are three main differences in the consumption culture in China: consumer habits, shopping habits, and preference of location.

In China, consumers tend to buy things they need frequently and not in bulk. This is different than how American consumers buy groceries because they tend to buy things they need in one go [13]. By not understanding China's consumption habits, Walmart has its stores sell things in bulk just like what they are doing in the US, which led to consumers finding Walmart less appealing. 
Chinese consumers also buy things without a list of what they want to purchase. They would go into markets and buy what they feel like they need, things from sale promotions, or from what they see other people buying [13]. This way of shopping contrasts how American consumers shop because they would buy things with a list that they made beforehand.

Chinese consumers prefer convenience, which means they prefer to live in places that they can benefit from. For example, when they go out for walks, they would want to buy things on the way back if there is a supermarket nearby [13]. However, most Walmart stores are built-in malls or somewhere inconvenient, which is not appealing to the Chinese audience. In America, people would live in the suburbs and enjoy driving to supermarkets.

\section{CONCLUSION}

\subsection{Conclusion}

In the previous content, we went through the current issues of Walmart China facing today. Then demonstrate some possible solutions of corporation's future benefit corresponds the trend in Chinese market and civilian's needs. Also, the utilization of the cultural aspects from both China and the United States illuminates the key to success of the strategic communications. The final goal of this SWOT analysis is to illustrate the current trend of the tremendous shifts from offline retiling to online ecommerce in China by the great example performed of Walmart China. In the end, Walmart China should involve structural reformation in the following few years in order to adapt the public's requirement and overcome the obstacle under the governmental policies and the misconception of intercultural communications.

\subsection{Recommendations}

1. Use language such as "environmentally friendly" "sustainable feature" in Walmart's advertising campaigns to indicate that they can accelerate environmental procession leading to financial increase. The Chinese government has issued a series of environmental policies to facilitate a delicate environment-kindly cities and Chinese consumers are also buying more green products as a trend.

2. Collaborate with more than one Chinese partnership of e-commerce not only JD.com also a corporation like Tencent which has a profound influence on both communication and marketing. Demand for grocery delivery is rising in China like it is in the U.S., which requires expensive logistical investments, working on Tencent WeChat small program allows easier access to carrying out efficiency, convenience, and replenishment.
3. Create an official template that includes crisis explanations and solutions to the media when a food scandal occurs. This can help Walmart to give a reasonable response within an hour and reduce the negative impact on the brand as the crisis continues to unfold.

4. Conduct a strategic meeting with board members to better understand the consumption culture in China. By understanding the consumption culture in China, Walmart can take action in changing their business model in China to better satisfy consumers and stand out against their competitors.

\section{REFERENCES}

[1] Team, T. (2021, June 30). Why Wal-Mart never picked up in china? Forbes. https://www.forbes.com/sites/greatspeculations/201 4/06/18/why-wal-mart-never-picked-up-inchina/?sh=78cf5ab17fb8.

[2] Ma, Y. (2021, April 26). China: Walmart store NUMBER 2020. Statista. https://www.statista.com/statistics/752119/chinawalmart-store-number/.

[3] Chu, F. (2020, January 7). US retail giants invest in strategic partnerships. SmartBrief. https://www.smartbrief.com/original/2020/01/usretail-giants-invest-strategic-partnerships.

[4] Anna, H. (2019, May 14). Why Walmart's China strategy focuses on grocery. https://digiday.com/retail/walmart-tackling-chinasgrocery-market/

[5] Textor, C., \& 21, J. (2020, July 21). China: Increase in delivery services due To COVID-19 by service TYPE 2020.2 Statista. https://www.statista.com/statistics/1112719/chinaincrease-in-delivery-services-due-to-covid-19-byservice-type/.

[6] Berthiaume, D. (2019, August 14). Walmart dramatically increases supply chain commitment in China.

https://chainstoreage.com/operations/walmartdramatically-increases-supply-chain-commitmentin-china.

[7] IvyPanda. (2020, May 30). Wal-Mart company's cross cultural communication - 1377 WORDS: Case Study example. https://ivypanda.com/essays/wal-martcompanys-cross-cultural-communication/

[8] Yufeng, G. (2019, July 26). AI in new retail in China: not just unmanned stores, Daxue Consulting https://daxueconsulting.com/artificial-intelligencenew-retail-china/. 
[9] Steffi, N. (2019, July 17). Emotional data in China: when emotions become measurable, Daxue Consulting https://daxueconsulting.com/emotionaldata-china/.

[10] Daxue Consulting Market Research China. (2021, February 23). Walmart in China: Market entry case study - Daxue consulting - market Research china. https://daxueconsulting.com/wal-mart-in-china/

[11] Team, T. (2014, April 2). Challenges Wal-Mart faces In Mexico and China. Forbes. https://www.forbes.com/sites/greatspeculations/20 14/04/02/challenges-wal-mart-faces-in-mexicoand-china/ $? \mathrm{sh}=622285 \mathrm{cb} 17 \mathrm{~d} 4$

[12] Pham, S. (2019, November 21). Walmart is doubling down on China with 500 new stores. CNN. https://edition.cnn.com/2019/11/21/busines s/walmart-china-stores/index.html.

[13] Huang, J., \& Jia, Y. (2015, April 30). Wal-Mart Development in Chinese Market: Problems and Countermeasures- Based on the Enterprise Culture and Ethics. http://www.cscanada.net/index.php/ibm/article/vie wFile/6806/pdf_132 